\title{
An Assessment of the Novel COVISTRESS Questionnaire: COVID-19 Impact on Physical Activity, Sedentary Action and Psychological Emotion
}

Ukadike Chris Ugbolue ${ }^{1,2,3, *}$, Martine Duclos ${ }^{4}\left(\mathbb{D}\right.$, , Constanta Urzeala ${ }^{5} \oplus$, Mickael Berthon ${ }^{6}$, Keri Kulik ${ }^{7}$, Aura Bota ${ }^{8}$, David Thivel ${ }^{9}$, Reza Bagheri ${ }^{10}$, Yaodong Gu ${ }^{1}{ }^{\circledR}$, Julien S. Baker ${ }^{1,11}{ }^{1}$, Nicolas Andant ${ }^{12}$, Bruno Pereira ${ }^{12}{ }^{(0)}$, Karine Rouffiac ${ }^{13}$, Maëlys Clinchamps ${ }^{14}{ }^{(0)}$, Frédéric Dutheil ${ }^{14}$ and on behalf of the COVISTRESS Network ${ }^{\dagger}$

1 Faculty of Sports Science, Ningbo University, Ningbo 315211, China; guyaodong@hotmail.com (Y.G.); jsbaker@hkbu.edu.hk (J.S.B.)

2 Institute for Clinical Exercise \& Health Science, School of Health and Life Sciences, University of the West of Scotland, South Lanarkshire G72 0LH, Scotland, UK

3 Department of Biomedical Engineering, University of Strathclyde, Glasgow G11XQ, UK

4 Department of Sport Medicine and Functional Exploration, University Hospital CHU G. Montpied, INRA, UNH, CRNH Auvergne, Clermont Auvergne University, Clermont-Ferrand, F-63000 Clermont-Ferrand, France; mduclos@chu-clermontferrand.fr

5 Sports and Motor Performance Department, Faculty of Physical Education and Sports, National University of Physical Education and Sports, 060057 Bucharest, Romania; constanta.urzeala@unefs.ro

6 LaPSCo, Catech, Université Clermont Auvergne, CNRS, F-63000 Clermont-Ferrand, France; mickael.berthon@uca.fr

7 Health and Physical Education Program, Indiana University of Pennsylvania, Bloomington, IN 47405-1006, USA; kskulik@iup.edu

8 Department of Teaching Staff Training, Faculty of Physical Education and Sports, National University of Physical Education and Sports, 060057 Bucharest, Romania; aurabota@ymail.com

9 Laboratory of Metabolic Adaptations to Exercise under Physiological and Pathological conditions (AME2P), Université Clermont Auvergne, CRNH Auvergne, F-63000 Clermont-Ferrand, France; david.thivel@uca.fr Department of Exercise Physiology, University of Isfahan, 8174673441 Isfahan, Iran; will.fivb@yahoo.com

11 Department of Sport, Physical Education and Health, Centre for Health and Exercise Science Research, Hong Kong Baptist University, Kowloon Tong 999077, Hong Kong, China

12 Biostatistics Unit, DRCI, University Hospital of Clermont-Ferrand, CHU Clermont-Ferrand, F-63000 Clermont-Ferrand, France; nandant@chu-clermontferrand.fr (N.A.); bpereira@chu-clermontferrand.fr (B.P.)

13 Preventive and Occupational Medicine, University Hospital of Clermont-Ferrand, CHU Clermont-Ferrand, F-63000 Clermont-Ferrand, France; krouffiac@chu-clermontferrand.fr

14 Physiological and Psychosocial Stress, LaPSCo, CNRS, Preventive and Occupational Medicine, WittyFit, University Hospital of Clermont-Ferrand, CHU Clermont-Ferrand, Université Clermont Auvergne, F-63000 Clermont-Ferrand, France; maelysclinchamps@gmail.com (M.C.); frederic.dutheil@uca.fr (F.D.)

* Correspondence: u.ugbolue@uws.ac.uk; Tel.: +44-(0)1698-283100 (ext. 8284)

+ The COVISTRESS network is headed by Pr. Frédéric Dutheil-CHU Clermont-Ferrand, Occupational and Environmental Medicine, 58 rue Montalembert, 63000 Clermont-Ferrand, France. Members of the research group are Nicolas Andant, Maélys Clinchamps, Stéphanie Mestres, Cécile Miele, Valentin Navel, Lénise Parreira, Bruno Pereira, Karine Rouffiac-CHU Clermont-Ferrand, France; Yves Boirie, Jean-Baptiste Bouillon-Minois, Martine Duclos, Maria Livia Fantini, Jeannot Schmidt, Stéphanie Tubert-Jeannin-Université Clermont Auvergne/CHU Clermont-Ferrand, France; Mickael Berthon, Pierre Chausse, Michael Dambrun, Sylvie Droit-Volet, Julien Guegan, Serge Guimond, Laurie Mondillon, Armelle Nugier, Pascal Huguet-Université Clermont Auvergne, CNRS, LAPSCO, France; Samuel Dewavrin-WittyFit, France; Fouad Marhar-CHU Toulouse, France; Geraldine Naughton, Amanda Benson-Swinburne University, Australia; Claus Lamm - University of Vienna, Austria; Vicky Drapeau -Université de Laval, Canada; Raimundo Avilés Dorlhiac_Universidad Finis Terrae, Chile; Benjamin Bustos-Universidad de Los Andes, Chile; Gu Yaodong-Ningbo University, China; Haifeng Zhang-Hebei Normal University, China; Peter Dieckmann-Copenhagen Academy for Medical Education and Simulation (CAMES), Denmark; Julien Baker, Binh Quach, Jiao Jiao, Yanping Duan, Gemma Gao, 
Wendy Y J Huang, Ka Lai Kelly Lau, Chun-Qing Zhang, Hong Kong Baptist University, China; Hijrah Nasir, Indonesia; Perluigi Cocco, Rosamaria Lecca, Monica Puligheddu, Michela Figorilli, Università di Cagliari, Italia; Morteza Charkhabi, Reza Bagheri-University of Isfahan, Iran; Daniela Pfabigan-University of Oslo, Norway; Peter Dieckmann, University of Stavanger, Norway; Samuel Antunes, David Neto, Pedro Almeida-Ordem dos Psicólogos Portugueses, ISPA-Instituto Universitário, Portugal; Maria João Gouveia-ISPA-Instituto Universitário, Portugal; Pedro Quinteiro-William James Center for Research, ISPA-Instituto Universitário; Constanta Urzeala-UNEFS, Romania; Benoit Dubuis-UNIGE, Switzerland; Juliette Lemaignen-Fondation INARTIS, Switzerland; Andy Liu-University of Taipei, Taiwan; Foued Saadaoui, King Abdulaziz University, Tunisia; Ukadike Chris Ugbolue, University of the West of Scotland, United Kingdom; Keri Kulik-Indiana University of Pennsylvania, USA; Kuan-chou Chen, National Taiwan University of Sport, Department of Sport Management, Taiwan.

Received: 6 September 2020; Accepted: 9 October 2020; Published: 19 October 2020

Abstract: Globally the COVID-19 pandemic outbreak has triggered an economic downturn and a rise in unemployment. As a result, global communities have had to face physical, health, psychological and socio-economical related stressors. The purpose of this study was to assess and report the impact of isolation and effect of coronavirus on selected psychological correlates associated with emotions. Following ethical approval, a mixed methods observational study was conducted using the validated COVISTRESS questionnaire. Two observational study scenarios were evaluated namely "Prior" to the COVID-19 outbreak and "Currently", i.e., during the COVID-19 pandemic. 10,121 participants from 67 countries completed the COVISTRESS questionnaire. From the questionnaire responses only questions that covered the participant's occupation; sociodemographic details, isolation and impact of coronavirus were selected. Further analyses were performed on output measures that included leisure time, physical activity, sedentary time and emotions. All output measures were evaluated using the Visual Analogue Scale (VAS) with an intensity ranging from 0-100. Descriptive statistics, Wilcoxon signed-rank test and Spearman correlational analysis were applied to the leisure time, physical activity, sedentary time and emotional feeling datasets; $p=0.05$ was set as the significance level. Both males and females displayed similar output measures. The Wilcoxon signed rank test showed significant differences with respect to "Prior" COVID-19 and "Currently" for sedentary activity $(Z=-40.462, p<0.001)$, physical activity $(Z=-30.751, p<0.001)$ and all other emotional feeling output measures. A moderate correlation between "Prior" COVID-19 and "Currently" was observed among the Males $(r=0.720)$ in comparison to the Females $(r=0.639)$ for sedentary activity while weaker correlations $(r<0.253)$ were observed for physical activity and emotional feeling measurements, respectively. Our study reported incremental differences in the physical and psychological output measures reported, i.e., "Prior" COVID-19 and "Currently". "Prior" COVID-19 and "Currently" participants increased their sedentary habits by $2.98 \%$, and the level of physical activity reduced by $2.42 \%$, depression levels increased by $21.62 \%$, anxiety levels increased by $16.71 \%$, and stress levels increased by $21.8 \%$. There were no correlations (r) between leisure, physical activity and sedentary action (i.e., "Prior" $=-0.071$; “Currently" $=-0.097$ ); no correlations ( $\mathrm{r}$ ) between leisure physical activity and emotion (i.e., $-0.071>\mathrm{r}>0.081$ ) for "Prior"; and poor correlations ( $\mathrm{r}$ ) between leisure, physical activity and sedentary action (i.e., $-0.078>\mathrm{r}>0.167$ ) for "Current". The correlations ( $r)$ between sedentary action and emotion for "Prior" and "Currently" were $(-0.100>r>0.075)$ and $(-0.040>r>0.041)$ respectively. The findings presented here indicate that the COVISTRESS project has created awareness in relation to the physical and psychological impact resulting from the COVID-19 pandemic. The findings have also highlighted individual distress caused by COVID-19 and associated health consequences for the global community.

Keywords: COVID-19; Severe Acute Respiratory Syndrome Coronavirus 2 (SARS-CoV-2); depression; anxiety; stress; distress 


\section{Introduction}

An investigation by the Chinese Centre for Disease Control and Prevention (CCDC) on 7 January 2020 identified a causative agent called Severe Acute Respiratory Syndrome Coronavirus 2 (SARS-CoV-2) from throat swab samples. This disease was classified as COVID-19 by the World Health Organisation (WHO) [1]. COVID-19 infected patients present with dry coughs, sore throats and fever; however, complications occur when these mild symptoms develop into septic shock, pulmonary oedema, organ failure, severe pneumonia and Acute Respiratory Distress Syndrome (ARDS) [2]. Older and obese citizens appear to be more vulnerable if complications develop and intensive care support is required if individual situations worsen due to underlying medical conditions or comorbidities. These comorbidities include cerebrovascular, endocrine, cardiovascular, digestive and respiratory diseases. Cases admitted into intensive care also reported abdominal pain, dyspnoea, dizziness and anorexia [3,4].

A global health emergency based on the COVID-19 outbreak was declared on the 30th of January 2020. It is evident that countries more susceptible to the COVID-19 situation are those with compromised, weak or vulnerable healthcare systems. As the spread of the COVID-19 pandemic continues to grow, efforts continue to be directed towards strategically implementing healthcare guidelines designed to interrupt its course and minimise effects. This means that healthcare systems on a global scale are all engaged in reducing COVID-19 transmission through early detection, isolation, rapid treatment and the execution of an organised and robust system to contact and trace COVID-19 victims and potential carriers of the virus [5]. On the 6th of August 2020, the WHO COVID-19 Situation Report-199 highlighted the fact that on a global scale, the situation statistically (new cases in the last $24 \mathrm{~h}$ ) had worsened and cases had risen to 18,614,177 (increase of 259,344) with 702,642 deaths (increase of 6488) recorded. This was in addition to new cases being recorded as high and still increasing [6]. In particular, the number of confirmed COVID-19 cases (new cases in the last $24 \mathrm{~h}$ ) and deaths (new cases in the last $24 \mathrm{~h}$ ) reported in terms of numbers (by WHO region) on the 6 of August 2020 were as follows: Africa, 848,053 (13,906) cases and 15,252 (502) deaths; Americas, 9,981,204 (139,362) cases and 372,008 (4,074) deaths; Eastern Mediterranean, 1,598,640 $(13,182)$ cases and 42,052 (451) deaths; Europe, 3,477,225 (25,178) cases and 215,168 (430) deaths; South-East Asia, 2,360,721 (61,288) cases and 49,572 (1003) deaths; and Western Pacific, 347,593 (6428) and 8577 (28) deaths [6].

In response to the global pandemic, funding for research into the pathophysiology of the virus to the sum of $€ 10,000,000$ from the EU has been invested to "contribute to a more efficient clinical management of patients infected with the virus, as well as public health preparedness and response" [7]. A total of $£ 20,000,000$ has been invested by the United Kingdom (UK) government into the development of a COVID-19 vaccine [8]. To date one COVID-19 vaccine has been approved whilst others are at the pre-clinical trial phase, Phase 1, Phase 2 and/or making transitions into Phase 3. Gam-COVID-Vac now known as Sputnik V was developed at the Gamaleya Research Institute in Moscow. The Ministry of Health of the Russian Federation approved this vaccine on 11th of August 2020. Despite Russia being the first country to speedily develop a COVID-19 vaccine (Sputnik V), the vaccine is yet to enter Phase 3 Clinical Trials, and experts have raised concerns about the vaccine's safety and efficacy [9]. In Scotland, the financial impact of COVID-19 has been supported by the Scottish Government with a goal to protect and secure their world-leading research programmes through the provision of a $£ 75$ million one-off increase in funding for Scotland's universities [10]. More recently, various independent and collaborative multidisciplinary related research studies on COVID-19 have been investigated in the area of equipment and manufacturing [11-14], pathophysiology [15-17], neurophysiology [18-21], radiology [22-25], psychology [26,27], diagnostics [28-32] and treatment [33-35].

Despite the funding provisions made available and with research studies initiated globally, the financial impact of COVID-19 among the white-collared and blue-collared workers continues to remain. On a global scale, the COVID-19 pandemic continues to affect overall efficiencies and productivity levels, livelihoods within and outside the health sector, as well as economies, which have 
resulted in an economic downward spiral. These negative impacts induced by COVID-19 triggered the initiation of this investigation termed COVISTRESS. There are no published findings using the COVISTRESS questionnaire on the physical and psychological impact of the COVID-19 pandemic in the general community nationally or from an international perspective. This mixed methods investigation, i.e., both qualitatively and quantitatively driven, utilises a customised questionnaire focused on studying the impact of the coronavirus on life issues and consequential development of STRESS particularly on individual lifestyle and work environment. The COVISTRESS questionnaire has been validated in-house using similar scientific rigour applied to the published JOBSTRESS* Randomised Trial [36]. The COVISTRESS questionnaire has been translated into nine languages and, to date, distributed in sixty-seven countries. The questionnaire, prior to administration, was translated into the native language of each different country. A native speaker of the country concerned checked the integrity of the translation, to ensure that none of the information regarding the questions was lost during translation. This confirmed that the questions were consistent in every country where the questionnaire was administered.

The questionnaire consists of nine sections requiring the participants in most sections to complete a Visual Analogue Scale (VAS) with an intensity scale ranging from 0-100. Different versions of the VAS have been reported by Dutheil and colleagues [36-38]. The nine sections from the COVISTRESS questionnaire cover information relating to epidemiological context, participant's COVID-19 knowledge, measure of stress and worries, participant's occupation, VAS and professions, parenthood and family, sociodemographic details, isolation and impact of coronavirus; and participant's health coverage. Extracted from the COVISTRESS questionnaire are three components namely leisure physical activity, sedentary action and emotions. It is envisaged that an evaluation of these selective components will provide health and wellbeing information and emotions associated with coronavirus stress and its psychological impacts on societies. These three components are important in understanding the influence coronavirus has had on the citizens of the world. Emerging evidence suggest that the Coronavirus pandemic has initiated a devastating threat to our public health, our lifestyles and our countries' economies. As a consequence of observing quarantine and social distancing measures as well as hospitalization and bed rest measures, physical inactivity brought about by immobilization could downgrade the capacity of organs to remain fully functional and operationally efficient. This means the vulnerability of our organs could potentially become compromised and unable to resist and fight off the likelihood of viral infections. These repercussions could thereby increase the risk of damage to the cardiovascular system, immune system, respiratory system, musculoskeletal system and the brain [39]. Aside from the physiological impact, psychological emotions and metal health factors can also play a role in increasing anxiety levels, loneliness and social isolation during lockdown [39-41]. Social isolation (an absence of social connections) and loneliness (subjective dissatisfaction with relationships) although considered as under-recognised determinants of health status [41], both have also been found to be predictors of cardiovascular disease, cognitive decline, increased depression and premature mortality [42-44]. The combination of the physiological related (i.e., physical activity, sedentary activity) and psychosocial related (i.e., emotion) variables have not been previously investigated in relation the COVID-19 pandemic.

Therefore, the aims of this study were to assess and report the impact of isolation and effect of coronavirus on leisure physical activity and sedentary action psychological correlates associated with emotional feelings. We hypothesized that the relationship "Prior" COVID-19 and "Currently" will show an increase in physical inactivity and sedentary measurements, and that these outcome measures will instigate definitive emotional feelings connected with anxiety, depression and stress. 


\section{Method}

\subsection{Participants}

Following ethical approval from the University hospital in France (Nos Ref.: 2020/CE 06) on the 9 of March 2020, a mixed methods observational study was conducted using the validated COVISTRESS questionnaire. 10,121 participants completed the questionnaire. All participants reviewed the information sheet and voluntarily provided written informed consent prior to participating in the study. Participants were given the freedom to withdraw from the study at any time without having to give reasons. Regarding the research on human participants, the procedures of this observational study complied with the provisions of the Declaration of Helsinki. The inclusion criteria were not restrictive, as both COVID-19 positive and negative participants were recruited onto the study irrespective of whether the participant had contact with a person infected with the virus or not. The principal investigator and co-investigators were interested to ascertain the impact that this pandemic had on the lives of the participants. This study is still active in terms of data collection and is an international collaboration between several Institutions (University Hospitals, Universities, The French National Centre for Scientific Research (French: Centre national de la recherche scientifique, CNRS), and Occupational Health).

\subsection{Output Measurements}

Participants were recruited via the application of the convenience and snowball sampling technique. During participant selection, all participants that satisfied the recruitment criteria were granted online access to the COVISTRESS questionnaire. The duration of the administration of the COVISTRESS questionnaire was 73 days (from 30th of March 2020 to 10th of June 2020). The participant selection, recruitment and advertisement were achieved through radio, television, fliers, posters, newspapers and online mediums including social networks such as Facebook, Twitter, etc. The anonymous online COVISTRESS questionnaire was completed with data including the participants' sociodemographic information, health and wellbeing information and psychosocial information. Quality assurance was maintained by ensuring only one questionnaire was submitted per IP address. A master spreadsheet was prepared using Microsoft Excel 2019 version 16.23 (Microsoft Corporation, Redmond, WA, USA) for data processing and analyses. Two observational study scenarios were evaluated namely "Prior" to COVID-19 pandemic and "Currently", i.e., during the COVID-19 period. From forty-five questions spread across the nine sections, only questions that covered the participant's occupation; sociodemographic details; and isolation and impact of Coronavirus were selected to analyse the three components, namely, leisure physical activity, sedentary action and emotions. According to the World Health Organisation [45], physical activity is defined as "any bodily movement produced by skeletal muscles that require energy expenditure. Popular ways to be active are through walking, cycling, sports and recreation, and can be done at any level of skill and for enjoyment". In line with the Public consultation on the draft WHO Guidelines on physical activity and sedentary behaviour for children and adolescents, adults and older adults 2020, sedentary action was defined as any very low energy expenditure activity that requires sitting or lying as the dominant posture [46]. All these components were evaluated using the VAS with an intensity scale ranging from $0-100$. In general, VAS is a psychometric response scale that can be used in questionnaires to assess occupational stress $[47,48]$.

In terms of the three components, the information requested was the following: Number of hours of leisure physical activity per week "Prior" to the Coronavirus Pandemic and "Currently"; Number of hours seated by day "Prior" to the Coronavirus Pandemic and "Currently"; Participants emotional feelings were categorised into Soothed/Anger (VAS Soothed/Anger) Prior to the Coronavirus Pandemic and Currently, Sadness/Joy (VAS Sadness/Joy) "Prior" to the Coronavirus Pandemic and "Currently", Peaceful/Excited (VAS Peaceful/Excited) "Prior" to the Coronavirus Pandemic and "Currently", Busy/Boredom (VAS Busy/Boredom) "Prior" to the Coronavirus Pandemic and "Currently". 
To holistically evaluate the three components an additional outcome measure was incorporated to ascertain how the participants felt about the passage of time. The VAS scale was used as a measure to assess the perception of time from the participants' perspective. The scale of measurement ranged from "time seems to go slowly" to "time flies very fast", and this was applied "Prior" to the Coronavirus Pandemic, "Currently", "During the day" and "During the week".

\subsection{Statistical Analysis}

Statistical analysis software IBM SPSS Statistics for Windows, Version 25.0. (IBM Corp., Armonk, NY, USA) was used to analyse the datasets. A Shapiro-Wilks test was used to ascertain whether the data was normally distributed. Descriptive statistics were provided, and a mixed methods approach was applied to the dataset to extract and assess emotional feeling outputs based on countries, gender, age and occupation. The "Prior" and "Currently" sets of score comparisons and associations within the three components, namely, leisure physical activity, sedentary action and emotions were performed using the Wilcoxon signed-rank test and Spearman correlation (r). A Spearman's correlation (r) between age and all the variables was also calculated. An association between the physical variables (leisure physical activity, sedentary action) and emotion was performed using the Spearman correlation (r) for the "Prior" variables and "Currently" variables, respectively. When implementing the Spearman's correlation, the $r$ values obtained varied between -1 and +1 where 1 is a perfect correlation and 0 represents no correlation [49,50]. Further interpretations of $r$ include $1>r \geq 0.8$ (Very Strong); $0.8>r \geq 0.6$ (Moderate); $0.6>r \geq 0.3$ (Fair) and $0.3>r \geq 0.1$ (Poor) [1,2]. $p<0.05$ was considered significant.

\section{Results}

The Shapiro-Wilks Test revealed a statistically significant difference $(p<0.001)$ indicating that the data was not normally distributed. As a result, we rejected the null hypothesis for a normal distribution. Out of a total of 10,121 participants that completed the COVISTRESS questionnaire, only 952 participants omitted recording their country of domicile, and 27 did not record their sex. A total of 9142 (6292 female (aged: $41.40 \pm 13.10$ years) and 2850 male (aged: $43.92 \pm 14.30$ years)) participants that fully completed the COVISTRESS questionnaire were recruited from 67 countries located on the following continents Africa, Asia, Australia, Europe, North America and South America.

Both males and females displayed similar output measures. Table 1 provides a display of the combined sex output measures. Males ("Prior" COVID-19: $13.09 \pm 6.40$; "Currently": $15.80 \pm 7.70$ ) produced a higher VAS scale in comparison to the Females ("Prior" COVID-19: $12.15 \pm 5.95$; "Currently": $15.25 \pm 7.55$ ) for the sedentary measurement, i.e., number of hours seated per day. A stronger correlation between "Prior" COVID-19 and "Currently" was also observed among the Males ( $r=0.720)$ in comparison to the Females $(r=0.639)$. In terms of physical activity measurement, i.e., number of hours of leisure physical activity per week, Males ("Prior" COVID-19: $10.39 \pm 8.61$; “Currently": $7.75 \pm 7.61$ ) produced higher VAS scale outputs when compared to Females ("Prior" COVID-19: 8.32 \pm 7.29 ; "Currently": $5.99 \pm 6.08$ ). A moderate correlation between "Prior" COVID-19 and "Currently" was observed among the Males $(r=0.541)$ in comparison to the Females $(r=0.502)$.

Regarding the emotional feeling measurement, Males produced higher VAS scale outputs in terms of rating their psychological emotions for soothed/anger ("Prior" COVID-19: $37.43 \pm 22.28$; "Currently": $49.57 \pm 25.74$ ), sadness/joy ("Prior" COVID-19: 68.06 \pm 20.35 ; “Currently": $51.54 \pm 24.34$ ), peaceful/excited ("Prior" COVID-19: $41.22 \pm 24.77$; "Currently": $42.72 \pm 24.13$ ), busy/boredom ("Prior" COVID-19: $21.18 \pm 19.67$; “Currently": $41.00 \pm 29.78$ ) than Females soothed/anger ("Prior" COVID-19: $38.44 \pm 23.16$; “Currently": $57.15 \pm 25.20$ ), sadness/joy ("Prior" COVID-19: $68.78 \pm 21.48$; "Currently": $44.97 \pm 24.89$ ), peaceful/excited ("Prior" COVID-19: $44.98 \pm 25.27$; "Currently": $48.77 \pm 25.24$ ), busy/boredom ("Prior" COVID-19: $18.44 \pm 19.31$; “Currently": $41.09 \pm 31.20$ ). Overall, both males $(\mathrm{r}<0.336)$ and females $(\mathrm{r}<0.192)$ produced a poor correlation between the VAS scale outputs "Prior" COVID-19 and "Currently". 
Table 1. Descriptive statistics showing the "Prior" and "Currently" dataset summary of the VAS intensity scale for the three components/output measures.

\begin{tabular}{|c|c|c|c|c|c|}
\hline Output Measures & $\begin{array}{l}\text { Assessment "Prior" } \\
\text { COVID-19 } \\
\text { (Mean } \pm \text { SD) }\end{array}$ & $\begin{array}{l}\text { Assessment "Currently" } \\
\text { during COVID-19 } \\
(\text { Mean } \pm \text { SD) }\end{array}$ & $\begin{array}{l}\text { Mean Difference } \\
\text { between "Prior" } \\
\text { and "Currently" }\end{array}$ & $\begin{array}{l}\text { Correlation (r) between } \\
\text { "Prior" and "Currently" }\end{array}$ & Statistical Significance \\
\hline Number of hours seated per day & $12.45 \pm 6.11$ & $15.43 \pm 7.60$ & 2.98 & 0.656 & $<0.001$ \\
\hline $\begin{array}{l}\text { Number of hours of leisure } \\
\text { physical activity per week }\end{array}$ & $8.97 \pm 7.79$ & $6.55 \pm 6.65$ & -2.42 & 0.503 & $<0.001$ \\
\hline a Soothed/Anger & $38.13 \pm 22.90$ & $54.84 \pm 25.60$ & 16.71 & 0.190 & $<0.001$ \\
\hline b Sadness/Joy & $68.56 \pm 21.14$ & $46.94 \pm 24.91$ & -21.62 & 0.191 & $<0.001$ \\
\hline Peaceful/Excited & $43.86 \pm 25.19$ & $46.93 \pm 25.06$ & 3.07 & 0.252 & $<0.001$ \\
\hline${ }^{\mathrm{c}}$ Busy/Bored & $19.27 \pm 19.46$ & $41.07 \pm 30.77$ & 21.8 & 0.253 & $<0.001$ \\
\hline
\end{tabular}

Note: ${ }^{a}$ indicates depression, which is represented as Sadness/Joy; ${ }^{b}$ indicates anxiety, which is represented as Soothed/Anger, and ${ }^{c}$ indicates stress levels, which are represented as

Busy/Bored. Correlation is significant at the 0.01 level ( 2 tailed) 
The Wilcoxon signed rank test showed significant differences for sedentary activity $(Z=-40.462$, $p<0.001)$ and physical activity $(Z=-30.751, p<0.001)$ with respect to "Prior" COVID-19 and "Currently". In terms of the emotional feelings "Prior" and "Currently", the Wilcoxon signed rank test results were as follows: soothed/anger $(Z=-39.970, p<0.001)$, sadness/joy $(Z=-50.217, p<0.001)$, peaceful/excited $(Z=-9.600, p<0.001)$ and busy/boredom $(Z=-47.256, p<0.001)$, respectively.

From 10,121 participants that completed the COVISTRESS questionnaire, only 7938 participants provided their occupational status. The following statuses were recorded (number of participant recordings): (1) Executive and superior intellectual occupation (included students in medicine, pharmacy and dentistry) (2944 participants); (2) Intermediary professions, e.g., Teachers, Administrative roles, Clergy, etc. (2342 participants); (3) Farmer (18 participants); (4) Artisan, merchant or entrepreneur (512 participants); (5) Worker (617 participants); (6) Student (677 participants); (7) Looking for a job (303 participants); (8) Retired (525 participants). The percentage participant occupation recordings are displayed in Figure 1.

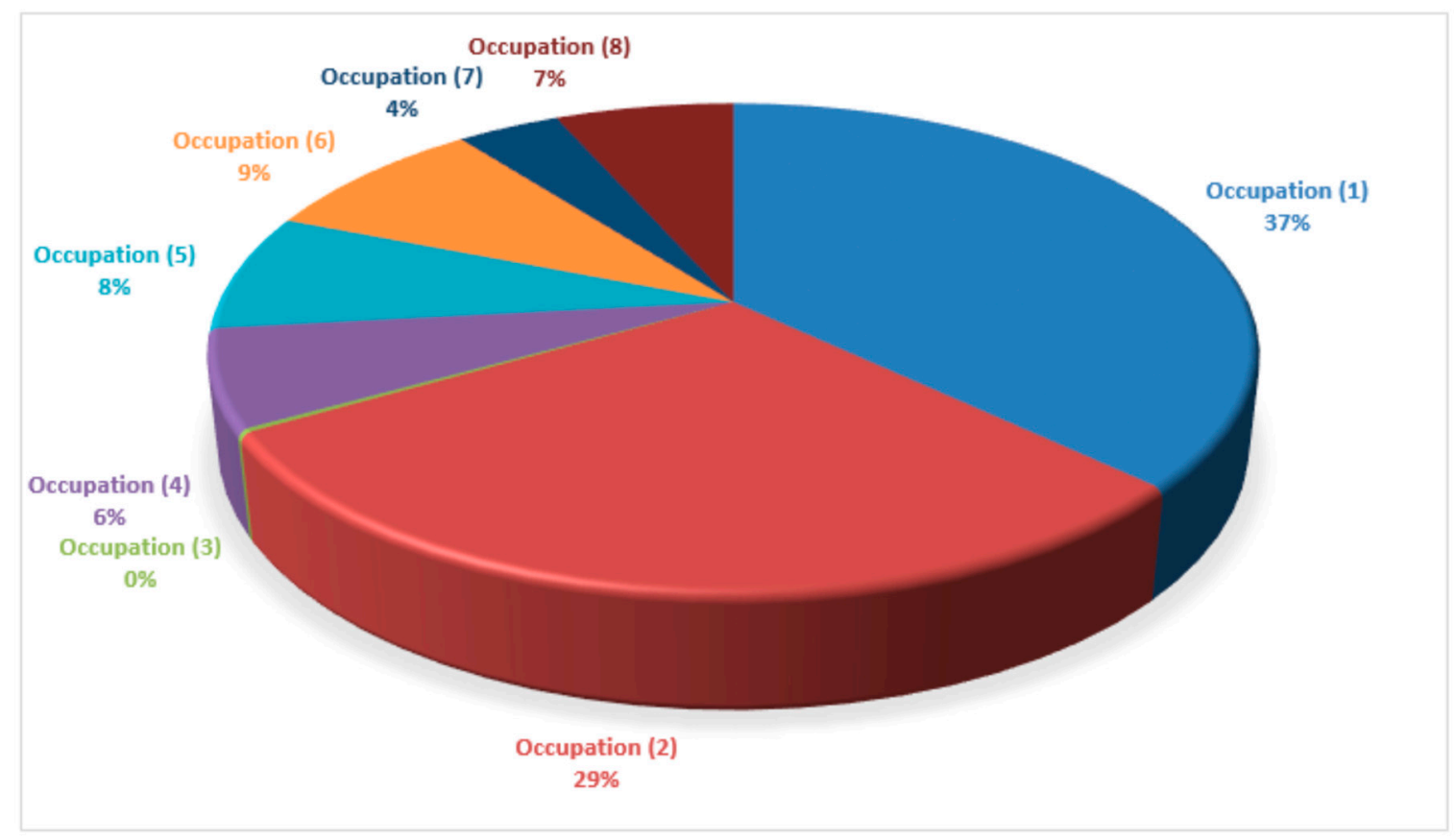

Figure 1. Pie chart display of the total occupation representation from the pool of participants that completed the COVISTRESS questionnaire.

There were no correlations ( $\mathrm{r}$ ) observed between age and all the measured variables (i.e., $-0.001>r>0.062$ ). The Wilcoxon signed rank test showed significant differences between the "Prior" Coronavirus Pandemic variable and the "Currently" $(\mathrm{Z}=-47.604, p<0.001)$; "During the day" $(Z=-43.510, p<0.001)$; and "During the week" $(Z=-41.346, p<0.001)$ variables. Significant differences were also exhibited between "Prior" and "During the Day" $(Z=-19.232, p<0.001)$; "Currently" and "During the Week" $(Z=-22.733, p<0.001)$ and "During the Day" and "During the Week" $(\mathrm{Z}=-5.706, p<0.001)$.

There were no correlations ( $\mathrm{r}$ ) between the leisure physical activity and sedentary action (i.e., "Prior" $=-0.071$; "Currently" $=-0.097)$. Although there were no correlations $(\mathrm{r})$ between leisure physical activity and emotion (i.e., $-0.071>\mathrm{r}>0.081$ ) for "Prior", the correlations (r) between leisure physical activity and sedentary action (i.e., $-0.078>\mathrm{r}>0.167$ ) for "Current" were poor. The correlations $(\mathrm{r}$ ) between sedentary action and emotion for "Prior" and "Currently" were $(-0.100>r>0.075)$ and $(-0.040>r>0.041)$, respectively. Figure 2 provides a bar chart description of how the participants felt about the passage of time. 
Further interpretations of $r$ include: $1>r \geq 0.8$ (Very Strong); $0.8>r \geq 0.6$ (Moderate); $0.6>r \geq 0.3$ (Fair) and $0.3>r \geq 0.1$ (Poor) [1,2]. $p<0.05$ was considered significant.

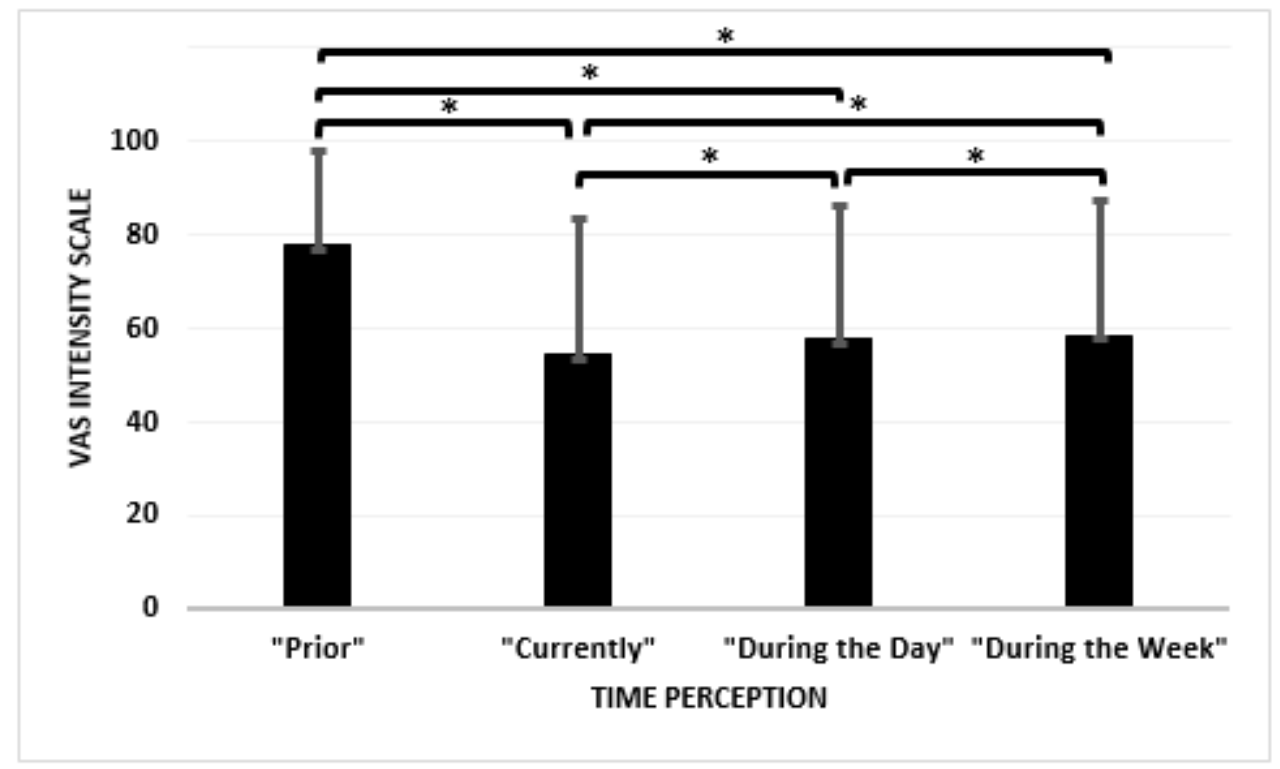

Figure 2. Bar chart description showing the perception of time based on the VAS intensity scale where time perception is measured from a scale from 1 to 100 and interpreted from "time seems to go slowly" to "time flies very fast". * indicates significance between variables.

\section{Discussion}

The results presented here provide an insight into the interactions between leisure, physical activity, sedentary action and emotions using the COVISTRESS VAS intensity scale. On completion of the current dataset analyses, a 90\% compliance was achieved with respect to completed COVISTRESS questionnaires from participants located in 67 different countries in the following continents Africa, Asia, Australia, Europe, North America and South America. Overall, males produced a higher VAS scale in comparison to the females for all three components, i.e., leisure, physical activity, sedentary action and emotions. Although, the Spearman correlation $(r)$ produced no correlation between age and all the measured variables, a moderate correlation was achieved between the "Prior" and "Currently" sets of score comparisons and associations for the sedentary action component; a fair correlation was attained for the leisure physical activity component, and poor correlations were observed for the emotional feelings component. The Wilcoxon signed rank test showed significant differences $(p<0.001)$ between all the perception of time variables, i.e., applied "Prior" to the Coronavirus Pandemic, "Currently", "During the day" and "During the week". Among the occupational statuses recorded within the COVISTRESS questionnaire, the executive and superior intellectual occupation (included students in medicine, pharmacy and dentistry) recorded the largest number of participant recordings. This accounted for 2944 participants, which represented 37\% from 7938 participants who provided their occupational statuses on the questionnaire. Our results were in agreement with our hypothesis.

To respond to the evolving unprecedented COVID-19 pandemic outbreak, an online validated self-reported COVISTRESS questionnaire was proposed and administered. This remote option was preferred to interview as using the COVISTRESS questionnaires provided a platform that truly reflected some of the key concerns necessary to understand selective physical and psychological components associated with stress in individual personal life's and work environment. The concept of using questionnaires also allowed us to broaden our database through the recruitment of participants from sixty-seven countries to date. Whilst the COVISTRESS questionnaire is not a diagnostic "qualitative tool" 
for COVID-19, it is pertinent that readers appreciate that the outputs reported here are simply a broad assessment highlighting symptoms associated with the COVID-19 situation in response to feedback from a wide variety of citizens scattered across sixty-seven different countries located on six different continents. To date, there has been a rapid growth in the number of publications into the physical health and psychological consequences of COVID-19. A few qualitatively driven studies have used customised COVID-19 related questionnaires to survey the public on issues related to the psychological impact of COVID-19 on mental health. Some of these research studies have emerged from countries such as Australia [51], Spain [52-54], India [55,56], Mexico [57], China [58-61], United Kingdom [62], USA [63], and Italy [64,65]. Based on the completed virtual and web-based surveys, the outcomes from these surveys suggest that levels and rates of psychological distress vary across countries. Spain reported $72 \%$ of their survey respondents had elevated psychological distress on the General Health Questionnaire-12 (GHQ-12) [52]. Australia reported that 78\% of respondents using their self-reported questionnaire observed that their mental health decreased since the outbreak, with $25.9 \%$ reported to have been very or extremely worried about contracting COVID-19, and 52.7\% worried about family and friends contracting COVID-19 [51]. India reported that during the COVID-19 pandemic $25 \%, 28 \%$, and $11.6 \%$ exhibited symptoms of moderate to extremely severe depression, anxiety and stress, respectively [66]. Mexico reported 50.3\% psychological distress as moderate to severe [57]. China reported in a cross-sectional survey from 52,730 participants conducted between 31 January and 10 February 2020 [61] where $29.3 \%$ of the respondents experienced mild to moderate psychological distress, and 5.1\% experienced severe distress. In another survey of 1210 members, Wang et al. [58] reported that $53.8 \%$ of participants rated the psychological impact of the COVID-19 outbreak as moderate to severe, $75 \%$ were worried about their family members contracting COVID-19, and rates of moderate to severe depression, anxiety and stress were $16.5 \%, 28.8 \%$, and $8.1 \%$ respectively. Four weeks later, in a follow-up survey, rates of depression, anxiety and stress remained unchanged [67].

Despite all this information provided via the surveys, there is still limited information on the impact that COVID-19 has had and continues to have on individuals' providing a powerful reason why more information and research is needed to fully understand the short and long term consequences that the COVID-19 pandemic has had on the mental, physical health and wellbeing of individuals. Our study reported incremental differences in the physical and psychological output measures reported, i.e., "Prior" COVID-19 and "Currently". These differences are representative indicators of the outcome measures reported, which when interpreted suggest that during COVID-19 (a) most participants adopted a sedentary habit, (b) physical activity per week decreased, (c) more people exhibited anger traits, (d) participants predominantly were sad, (e) participants appeared not at peace with themselves, and (f) a large proportion of participants were bored. In terms of directionality of influences particularly between the physical and emotion variables, our results showed that the associations between the physical variables (sedentary activity and physical activity) and the emotional ones were poor at best. With respect to the emotional feeling measurements "Prior" to COVID-19 and "Currently", participants increased their sedentary habits by $2.98 \%$, the level of physical activity reduced by $2.42 \%$, depression levels increased by $21.62 \%$, anxiety levels increased by $16.71 \%$, and stress levels increased by $21.8 \%$. These output measures agree with earlier reported levels of depression, anxiety and stress from different countries. These worrying statistics from the reported studies on COVID-19 demonstrate the raised psychological distress in the general community and countries at large.

This study is a novel study using the COVISTRESS questionnaire, as a limitation our study did not cover quality of life in terms of care, diagnosis, treatment and rehabilitation. Quality assurance was maintained by ensuring only one questionnaire was submitted per IP address. Nevertheless, it was difficult to control, restrict and monitor all participants remotely, i.e., it is possible the same participant could have submitted several questionnaires from different IP addresses. Research by William A. Rushing suggests that marital status and rates of mental health are related [68]. However, the marital status of all participants was not accounted for in this study. Although 10,121 participants that completed the COVISTRESS questionnaires were randomised, the occupational pool of participants 
was small and could have been larger. This study consisted of a greater proportion of females to males. Unfortunately, gender balance could not be controlled for. Consideration was not given to the fact that different countries/continents experienced COVID-19 at different times, as different rates of evolution and measures to cope with COVID-19 were adopted. Neither countries nor the phase (in terms of confinement measures) were controlled for in this study.

Future studies need to continue to provide high quality research that explores the impact of COVID-19 globally. This collaborative effort could foster the development of community and healthcare support systems, treatment and prevention efforts and provide informed evidence-based policy decisions that could yield meaningful assistance and preventative measures. These measures may benefit vulnerable individuals in society who are at risk of poor quality of life influenced by physical and psychological health related symptoms associated with the unprecedented and ongoing COVID-19 pandemic.

\section{Conclusions}

The goals of this study were achieved through the effective use and interpretation of the COVISTRESS questionnaire. A detailed assessment and report on the impact of isolation and the effect of coronavirus on selected psychological correlates associated with emotions were presented in this study. The findings indicate that the COVISTRESS project has created awareness in relation to the physical and psychological impact resulting from the COVID-19 pandemic. Although more data is still being collated, the current findings have highlighted individual distress caused by COVID-19 and associated health consequences for the global community.

Author Contributions: Conceptualization, F.D., M.C. and U.C.U.; Methodology, U.C.U., C.U., A.B. and F.D.; Software, M.C., M.B. and F.D.; Validation, F.D. and M.C.; Formal Analysis, U.C.U., C.U., A.B.; Investigation, F.D., U.C.U., M.C.; Resources, F.D.; Data Curation, F.D., M.C., K.K., Y.G., K.R., N.A., B.P.; and R.B.; Writing-Original Draft Preparation, U.C.U.; Writing-Review \& Editing, U.C.U., J.S.B., D.T., M.D., C.U., A.B.; Visualization, F.D.; Supervision, F.D., M.C.; Project Administration, F.D., M.C., U.C.U., J.S.B.; Funding Acquisition, F.D. All authors have read and agreed to the published version of the manuscript.

Funding: This project was undertaken as part of a research grant awarded by CNRS-Institut National des Sciences Biologiques; Laboratoire de Psychologie Sociale et Cognitive UMR 6024 UCA-CNRS (LAPSCO); and the Centre Hospitalier Universitaire (CHU) Clermont-Ferrand. The Article Processing Charges (APC) was funded by Professor Frédéric Dutheil and the team at the Centre Hospitalier Universitaire (CHU) Clermont-Ferrand.

Acknowledgments: The authors would like to thank all the participants involved in the study. The authors would also like to thank the ethics committees located in the 67 countries who granted us access to participants.

Conflicts of Interest: The authors declare no conflict of interest.

\section{References}

1. World Health Organization. WHO Director-General's Remarks at the Media Briefing on 2019-nCoV on 11 February 2020; World Health Organization: Geneva, Switzerland, 2020; Volume 10, Available online: https://www.who.int/dg/speeches/detail/who-director-general-s-remarks-at-the-mediabriefing-on-2019-ncov-on-11-february-2020 (accessed on 6 August 2020).

2. Chen, N.; Zhou, M.; Dong, X.; Qu, J.; Gong, F.; Han, Y.; Qiu, Y.; Wang, J.; Liu, Y.; Wei, Y. Epidemiological and clinical characteristics of 99 cases of 2019 novel coronavirus pneumonia in Wuhan, China: A descriptive study. Lancet 2020, 395, 507-513. [CrossRef]

3. Sohrabi, C.; Alsafi, Z.; O’Neill, N.; Khan, M.; Kerwan, A.; Al-Jabir, A.; Iosifidis, C.; Agha, R. World Health Organization declares global emergency: A review of the 2019 novel coronavirus (COVID-19). Int. J. Surg. 2020, 76, 71-76. [CrossRef]

4. Wang, D.; Hu, B.; Hu, C.; Zhu, F.; Liu, X.; Zhang, J.; Wang, B.; Xiang, H.; Cheng, Z.; Xiong, Y. Clinical characteristics of 138 hospitalized patients with 2019 novel coronavirus-infected pneumonia in Wuhan, China. JAMA 2020, 323, 1061-1069. [CrossRef] [PubMed]

5. World Health Organization. Novel Coronavirus(2019-nCoV), Situation Report-12; World Health Organization: Geneva, Switzerland, 2020. 
6. World Health Organization. Coronavirus Disease (COVID-19): Situation Report, 199; World Health Organization: Geneva, Switzerland, 2020.

7. European Commission. Coronavirus: EU Mobilises $€ 10$ Million for Research; European Commission: Brussels, Belgium, 2020.

8. BBC. Coronavirus: UK Donates £20m to Speed up Vaccine; BBC: London, UK, 2020.

9. The Regulatory Affairs Professionals Society (RAPS)-COVID-19 Vaccine Tracker. Available online: https:// www.raps.org/news-and-articles/news-articles/2020/3/covid-19-vaccine-tracker (accessed on 6 August 2020).

10. $£ 75$ Million Boost for Scottish University Research. One-off Government Payment to Help Mitigate Financial Effects of COVID-19. 2020. Available online: https://www.gov.scot/news/minister-announces-gbp-75mboost-for-university-research/ (accessed on 6 August 2020).

11. Kumar, M.S.; Raut, R.D.; Narwane, V.S.; Narkhede, B.E. Applications of industry 4.0 to overcome the COVID-19 operational challenges. Diabetes Metab. Syndr. Clin. Res. Rev. 2020, 14, 1283-1289. [CrossRef] [PubMed]

12. Brun, D.; Curti, C.; Mekideche, T.; Benech, A.; Hounliasso, I.; Lamy, E.; Castera, C.; Rathelot, P.; Vanelle, P. Stockpiled N95 respirator/surgical mask release beyond manufacturer-designated shelf-life: A French experience. J. Hosp. Infect. 2020, 106, 258-263. [CrossRef] [PubMed]

13. Plana, D.; Tian, E.; Cramer, A.K.; Yang, H.; Carmack, M.M.; Sinha, M.S.; Bourgeois, F.T.; Yu, S.H.; Masse, P.; Boyer, J. Assessing the quality of nontraditional N95 filtering face-piece respirators available during the COVID-19 pandemic. medRxiv 2020. [CrossRef]

14. Tarfaoui, M.; Nachtane, M.; Goda, I.; Qureshi, Y.; Benyahia, H. 3D Printing to Support the Shortage in Personal Protective Equipment Caused by COVID-19 Pandemic. Materials 2020, 13, 3339. [CrossRef]

15. Hyoju, S.K.; Zaborina, O.; van Goor, H. SARS-CoV-2 and the sympathetic immune response: Dampening inflammation with antihypertensive drugs (Clonidine and Propranolol). Med. Hypotheses 2020, 144, 110039. [CrossRef]

16. Wiese, O.; Zemlin, A.E.; Pillay, T.S. Molecules in pathogenesis: Angiotensin converting enzyme 2 (ACE2). J. Clin. Pathol. 2020. [CrossRef]

17. Malayala, S.V.; Raza, A. A Case of COVID-19-Induced Vestibular Neuritis. Cureus 2020, 12, e8918. [CrossRef]

18. Assenza, G.; Lanzone, J.; Brigo, F.; Coppola, A.; Di Gennaro, G.; Di Lazzaro, V.; Ricci, L.; Romigi, A.; Tombini, M.; Mecarelli, O. Epilepsy Care in the Time of COVID-19 Pandemic in Italy: Risk Factors for Seizure Worsening. Front. Neurol. 2020, 11, 737. [CrossRef]

19. Grippo, A.; Assenza, G.; Scarpino, M.; Broglia, L.; Cilea, R.; Galimberti, C.A.; Lanzo, G.; Michelucci, R.; Tassi, L.; Vergari, M. Electroencephalography during SARS-CoV-2 outbreak: Practical recommendations from the task force of the Italian Society of Neurophysiology (SINC), the Italian League Against Epilepsy (LICE), and the Italian Association of Neurophysiology Technologists (AITN). Neurol. Sci. 2020, 41, 2345-2351.

20. Bhaskar, S.; Bradley, S.; Israeli-Korn, S.; Menon, B.; Chattu, V.K.; Thomas, P.; Chawla, J.; Kumar, R.; Prandi, P.; Ray, D. Chronic neurology in COVID-19 era: Clinical considerations and recommendations from the REPROGRAM Consortium. Front. Neurol. 2020, 11, 664. [CrossRef] [PubMed]

21. Manganotti, P.; Bellavita, G.; D'Acunto, L.; Tommasini, V.; Fabris, M.; Sartori, A.; Bonzi, L.; Buoite Stella, A.; Pesavento, V. Clinical neurophysiology and cerebrospinal liquor analysis to detect Guillain Barré syndrome and polyneuritis cranialis in COVID-19 patients: A case series. J. Med. Virol. 2020. [CrossRef]

22. Polvoy, I.; Flavell, R.R.; Ohliger, M.; Rosenberg, O.; Wilson, D.M. Nuclear imaging of bacterial infection-state of the art and future directions. J. Nucl. Med. 2020,61, jnumed-120. [CrossRef]

23. Jiang, M.D.; Zu, Z.Y.; Schoepf, U.J.; Savage, R.H.; Zhang, X.L.; Lu, G.M.; Zhang, L.J. Current Status of Etiology, Epidemiology, Clinical Manifestations and Imagings for COVID-19. Korean J. Radiol. 2020, 21, 21. [CrossRef] [PubMed]

24. Jung, J.I. Radiologists' Solutions for COVID-19 in Korea. Korean J. Radiol. 2020, 21, 21. [CrossRef] [PubMed]

25. Park, B.; Park, J.; Lim, J.-K.; Shin, K.M.; Lee, J.; Seo, H.; Lee, Y.H.; Heo, J.; Lee, W.K.; Kim, J.Y. Prognostic Implication of Volumetric Quantitative CT Analysis in Patients with COVID-19: A Multicenter Study in Daegu, Korea. Korean J. Radiol. 2020, 21, 1256. [CrossRef]

26. Wang, L.-Q.; Zhang, M.; Liu, G.-M.; Nan, S.-Y.; Li, T.; Xu, L.; Xue, Y.; Zhang, M.; Wang, L.; Qu, Y.-D. Psychological impact of Coronavirus Disease 2019 (COVID-19) epidemic on medical staff in different posts in China: A multicenter study. J. Psychiatr. Res. 2020, 129, 198-205. [CrossRef] 
27. Huang, L.; Lei, W.; Xu, F.; Liu, H.; Yu, L. Emotional responses and coping strategies in nurses and nursing students during Covid-19 outbreak: A comparative study. PLoS ONE 2020, 15, e0237303. [CrossRef]

28. Fox-Lewis, S.; Muttaiyah, S.; Rahnama, F.; McAuliffe, G.; Roberts, S. An understanding of discordant SARS-CoV-2 test results: An examination of the data from a central Auckland laboratory. N. Z. Med. J. 2020, 133, 81-88. [PubMed]

29. Campioli, C.C.; Cevallos, E.C.; Assi, M.; Patel, R.; Binnicker, M.J.; O’Horo, J.C. Clinical predictors and timing of cessation of viral RNA shedding in patients with COVID-19. J. Clin. Virol. 2020, 130, 104577. [CrossRef] [PubMed]

30. Mahendiratta, S.; Batra, G.; Sarma, P.; Kumar, H.; Bansal, S.; Kumar, S.; Prakash, A.; Sehgal, R.; Medhi, B. Molecular diagnosis of COVID-19 in different biologic matrix, their diagnostic validity and clinical relevance: A systematic review. Life Sci. 2020, 258, 118207. [CrossRef] [PubMed]

31. Perkmann, T.; Perkmann-Nagele, N.; Breyer, M.-K.; Breyer-Kohansal, R.; Burghuber, O.C.; Hartl, S.; Aletaha, D.; Sieghart, D.; Quehenberger, P.; Marculescu, R. Side by side comparison of three fully automated SARS-CoV-2 antibody assays with a focus on specificity. medRxiv 2020. [CrossRef] [PubMed]

32. De Smet, K.; De Smet, D.; Ryckaert, T.; Laridon, E.; Heremans, B.; Vandenbulcke, R.; Demedts, I.; Bouckaert, B.; Gryspeerdt, S.; Martens, G.A. Diagnostic Performance of Chest CT for SARS-CoV-2 Infection in Individuals with or without COVID-19 Symptoms. Radiology 2020, 202708. [CrossRef] [PubMed]

33. Valle, C.; Martin, B.; Touret, F.; Shannon, A.; Canard, B.; Guillemot, J.C.; Coutard, B.; Decroly, E. Drugs against SARS-CoV-2: What do we know about their mode of action? Rev. Med. Virol. 2020, e2143. [CrossRef]

34. Weisberg, E.; Parent, A.; Yang, P.L.; Sattler, M.; Liu, Q.; Liu, Q.; Wang, J.; Meng, C.; Buhrlage, S.J.; Gray, N. Repurposing of Kinase Inhibitors for Treatment of COVID-19. Pharm. Res. 2020, 37, 1-29. [CrossRef] [PubMed]

35. Shamim, S.; Khan, M.; Kharaba, Z.J.; Ijaz, M.; Murtaza, G. Potential strategies for combating COVID-19. Arch. Virol. 2020, 1-20. [CrossRef]

36. Dutheil, F.; Trousselard, M.; Perrier, C.; Lac, G.; Chamoux, A.; Duclos, M.; Naughton, G.; Mnatzaganian, G.; Schmidt, J. Urinary interleukin-8 is a biomarker of stress in emergency physicians, especially with advancing age-The JOBSTRESS* randomized trial. PLOS ONE 2013, 8, e71658. [CrossRef]

37. Dutheil, F.; Pereira, B.; Moustafa, F.; Naughton, G.; Lesage, F.-X.; Lambert, C. At-risk and intervention thresholds of occupational stress using a visual analogue scale. PLoS ONE 2017, 12, e0178948. [CrossRef]

38. Dutheil, F.; Boudet, G.; Perrier, C.; Lac, G.; Ouchchane, L.; Chamoux, A.; Duclos, M.; Schmidt, J. JOBSTRESS study: Comparison of heart rate variability in emergency physicians working a 24-hour shift or a 14-hour night shift-A randomized trial. Int. J. Cardiol. 2012, 158, 322-325. [CrossRef] [PubMed]

39. Woods, J.; Hutchinson, N.T.; Powers, S.K.; Roberts, W.O.; Gomez-Cabrera, M.C.; Radak, Z.; Berkes, I.; Boros, A.; Boldogh, I.; Leeuwenburgh, C. The COVID-19 pandemic and physical activity. Sports Med. Health Sci. 2020, 2, 55-64. [CrossRef]

40. Smith, B.J.; Lim, M.H. How the COVID-19 pandemic is focusing attention on loneliness and social isolation. Public Health Res. Pract. 2020, 30, e3022008. [CrossRef]

41. Seeman, T.E. Health promoting effects of friends and family on health outcomes in older adults. Am. J. Health Promot. 2000, 14, 362-370. [CrossRef] [PubMed]

42. Hawkley, L.C.; Cacioppo, J.T. Loneliness matters: A theoretical and empirical review of consequences and mechanisms. Ann. Behav. Med. 2010, 40, 218-227. [CrossRef]

43. Shankar, A.; McMunn, A.; Banks, J.; Steptoe, A. Loneliness, social isolation, and behavioral and biological health indicators in older adults. Health Psychol. 2011, 30, 377. [CrossRef]

44. Luo, Y.; Hawkley, L.C.; Waite, L.J.; Cacioppo, J.T. Loneliness, health, and mortality in old age: A national longitudinal study. Soc. Sci. Med. 2012, 74, 907-914. [CrossRef]

45. World Health Organisation-Physical Activity. Available online: https://www.who.int/health-topics/physicalactivity\#tab=tab_1 (accessed on 6 August 2020).

46. WHO Guidelines on Physical Activity and Sedentary Behaviour for Children and Adolescents, Adults and Older Adults (DRAFT-for Consultation). 2020. Available online: https: //www.who.int/docs/default-source/physical-activity/call-for-consultation/draft-guideline-on-physicalactivity-and-sedentray-behaviour.pdf?sfvrsn=ddf523d5_4\#: \{\}:text=For\%20adults\%2C\%20sedentary\% 20behaviour\%20is, and\%20community\%20settings\%20and\%20transportation (accessed on 6 August 2020). 
47. Lesage, F.; Berjot, S. Validity of occupational stress assessment using a visual analogue scale. Occup. Med. 2011, 61, 434-436. [CrossRef]

48. Lesage, F.-X.; Berjot, S.; Deschamps, F. Clinical stress assessment using a visual analogue scale. Occup. Med. 2012, 62, 600-605. [CrossRef]

49. Akoglu, H. User's guide to correlation coefficients. Turk. J. Emerg. Med. 2018, 18, 91-93. [CrossRef]

50. Chan, Y.H. Biostatistics 104: Correlational analysis. Singap. Med. J. 2003, 44, 614-619.

51. Newby, J.M.; O'Moore, K.; Tang, S.; Christensen, H.; Faasse, K. Acute mental health responses during the COVID-19 pandemic in Australia. PLoS ONE 2020, 15, e0236562. [CrossRef] [PubMed]

52. Gómez-Salgado, J.; Andrés-Villas, M.; Domínguez-Salas, S.; Díaz-Milanés, D.; Ruiz-Frutos, C. Related Health Factors of Psychological Distress During the COVID-19 Pandemic in Spain. Int. J. Environ. Res. Public Health 2020, 17, 3947. [CrossRef] [PubMed]

53. Ozamiz-Etxebarria, N.; Dosil-Santamaria, M.; Picaza-Gorrochategui, M.; Idoiaga-Mondragon, N. Stress, anxiety, and depression levels in the initial stage of the COVID-19 outbreak in a population sample in the northern Spain. Cadernos de Saúde Pública 2020, 36, e00054020. [CrossRef] [PubMed]

54. Rodríguez-Rey, R.; Garrido-Hernansaiz, H.; Collado, S. Psychological impact of COVID-19 in Spain: Early data report. Psychol. Trauma Theory Res. Pract. Policy 2020, 12, 550-552. [CrossRef] [PubMed]

55. Kochhar, A.S.; Bhasin, R.; Kochhar, G.K.; Dadlani, H.; Mehta, V.V.; Kaur, R.; Bhasin, C.K. Lockdown of 1.3 billion people in India during Covid-19 pandemic: A survey of its impact on mental health. Asian J. Psychiatry 2020, 54, 102213. [CrossRef]

56. Rehman, U.; Shahnawaz, M.G.; Khan, N.H.; Kharshiing, K.D.; Khursheed, M.; Gupta, K.; Kashyap, D.; Uniyal, R. Depression, Anxiety and Stress Among Indians in Times of Covid-19 Lockdown. Community Ment. Health J. 2020, 1-7. [CrossRef] [PubMed]

57. Cortés-Álvarez, N.Y.; Piñeiro-Lamas, R.; Vuelvas-Olmos, C.R. Psychological Effects and Associated Factors of COVID-19 in a Mexican Sample. Disaster Med. Public Health Prep. 2020, 1-12. [CrossRef] [PubMed]

58. Wang, C.; Pan, R.; Wan, X.; Tan, Y.; Xu, L.; Ho, C.S.; Ho, R.C. Immediate Psychological Responses and Associated Factors during the Initial Stage of the 2019 Coronavirus Disease (COVID-19) Epidemic among the General Population in China. Int. J. Environ. Res. Public Health 2020, 17, 1729. [CrossRef] [PubMed]

59. Lai, J.; Ma, S.; Wang, Y.; Cai, Z.; Hu, J.; Wei, N.; Wu, J.; Du, H.; Chen, T.; Li, R.; et al. Factors Associated With Mental Health Outcomes Among Health Care Workers Exposed to Coronavirus Disease 2019. JAMA Netw. Open 2020, 3, e203976. [CrossRef] [PubMed]

60. Zhang, Y.; Ma, Z.F. Impact of the COVID-19 Pandemic on Mental Health and Quality of Life among Local Residents in Liaoning Province, China: A Cross-Sectional Study. Int. J. Environ. Res. Public Health 2020, $17,2381$. [CrossRef] [PubMed]

61. Qiu, J.; Shen, B.; Zhao, M.; Wang, Z.; Xie, B.; Xu, Y. A nationwide survey of psychological distress among Chinese people in the COVID-19 epidemic: Implications and policy recommendations. Gen. Psychiatry 2020, 33, e100213. [CrossRef]

62. Smith, L.; Jacob, L.; Yakkundi, A.; McDermott, D.; Armstrong, N.C.; Barnett, Y.; López-Sánchez, G.F.; Martin, S.; Butler, L.; Tully, M.A. Correlates of symptoms of anxiety and depression and mental wellbeing associated with COVID-19: A cross-sectional study of UK-based respondents. Psychiatry Res. 2020, 291, 113138. [CrossRef]

63. Liu, C.H.; Zhang, E.; Wong, G.T.F.; Hyun, S.; Hahm, H.C. Factors associated with depression, anxiety, and PTSD symptomatology during the COVID-19 pandemic: Clinical implications for U.S. young adult mental health. Psychiatry Res. 2020, 290, 113172. [CrossRef] [PubMed]

64. Cerami, C.; Santi, G.C.; Galandra, C.; Dodich, A.; Cappa, S.F.; Vecchi, T.; Crespi, C. Covid-19 Outbreak in Italy: Are We Ready for the Psychosocial and the Economic Crisis? Baseline Findings From the PsyCovid Study. Front. Psychiatry 2020, 11, 556. [CrossRef] [PubMed]

65. Mazza, C.; Ricci, E.; Biondi, S.; Colasanti, M.; Ferracuti, S.; Napoli, C.; Roma, P. A Nationwide Survey of Psychological Distress among Italian People during the COVID-19 Pandemic: Immediate Psychological Responses and Associated Factors. Int. J. Environ. Res. Public Health 2020, 17, 3165. [CrossRef] [PubMed]

66. Verma, S.; Mishra, A. Depression, anxiety, and stress and socio-demographic correlates among general Indian public during COVID-19. Int. J. Soc. Psychiatry 2020, 66, 756-762. [CrossRef] 
67. Wang, C.; Pan, R.; Wan, X.; Tan, Y.; Xu, L.; McIntyre, R.S.; Choo, F.N.; Tran, B.; Ho, R.; Sharma, V.K.; et al. A longitudinal study on the mental health of general population during the COVID-19 epidemic in China. Brain Behav. Immun. 2020, 87, 40-48. [CrossRef]

68. Rushing, W.A. Marital status and mental disorder: Evidence in favor of a behavioral model. Soc. Forces 1979, 58, 540-556. [CrossRef]

Publisher's Note: MDPI stays neutral with regard to jurisdictional claims in published maps and institutional affiliations.

(C) 2020 by the authors. Licensee MDPI, Basel, Switzerland. This article is an open access article distributed under the terms and conditions of the Creative Commons Attribution (CC BY) license (http://creativecommons.org/licenses/by/4.0/). 